\title{
A EDUCAÇÃO BÁSICA DE QUALIDADE COMO DIREITO DE TODO SER HUMANO
}

THE QUALITY OF BASIC EDUCATION AS BEING OF ALL HUMAN RIGHT

\author{
${ }^{1}$ Beatriz de lima Fernandes Gottardo \\ ${ }^{2}$ Joelma Vieira de Queiroz Carneiro
}

\section{RESUMO}

No presente artigo, pretendemos abordar a questão educação básica como um direito de todo ser humano. Para tal, utilizaremos dados empíricos, bem como,revisão bibliográfica no âmbito nacional e internacional. Primeiramente, o artigo vem falar de um modelo ideal de educação básica de qualidade para todos, fazendo contornos gerais do panorama mundial, até adentrar especificamente a situação da educação no Brasil. Abordaremos no texto um estudo dos diversos dispositivos normativos existentes no Brasil que tratam sobre a necessidade de garantir a educação básica de qualidade, de forma inclusiva, que atenda as diferentes necessidades dos alunos nas diversas regiões do nosso país, e assim, tentar encontrar soluções para os problemas que enfrentamos ao tentar levar a educação de qualidade para todos. Por fim, trataremos de questões referentes a garantia do direito à educação no plano internacional, apontando os dispositivos legais que garantem este direito bem como abordaremos o principio da dignidade da pessoa humana como meio para a efetivação desse direito.

Palavras-chave: Educação básica de qualidade, Garantia de direitos humanos, Direitos fundamentais, Direito à educação

\footnotetext{
${ }^{1}$ Mestre em direito pela Centro Universitário de João Pessoa - UNIPÊ, Paraíba (Brasil). E-mail: bialfn@hotmail.com

${ }^{2}$ Mestre em Direito pelo Centro Universitário de João Pessoa - UNIPÊ, Paraíba (Brasil). Agente Administrativa pela Prefeitura Municipal de Livramento - PML, Paraíba (Brasil). E-mail: joelma_vqc@ @otmail.com
} 


\begin{abstract}
In this article, we address the question basic education as a right of every human being. To do this, we will use empirical data as well as literature review in the national and international levels. First, the article is talking about an ideal model of quality basic education for all, making general contours of the world stage, to specifically enter the state of education in Brazil. We discuss the text a study of the various existing regulatory provisions in Brazil that deal with the need to ensure quality basic education in an inclusive way that meets the different needs of students in different regions of our country, and thus try to find solutions to the problems we face when trying to bring quality education to all. Finally, we will address issues related to guaranteeing the right to education at the international level, pointing out the legal provisions that guarantee this right and approach the principle of human dignity as a means for the realization of this right.
\end{abstract}

Keywords: Quality basic education, Guarantee human rights, Fundamental rights, Right to education 


\section{CONSIDERAÇÕES INTRODUTÓRIAS}

O presente trabalho tem por finalidade abordar a questão da educação básica como um direito de todo ser humano, sendo este um direito fundamental protegido pela nossa Constituição de 1988 e também por diversas normas internacionais que garantem este direito.

No primeiro tópico do nosso estudo, traremos um panorama da situação da educação básica no Brasil e no mundo, e o que tem sido feito para alcançar a educação básica de qualidade para todas as crianças e adolescentes.

No segundo tópico, trataremos da garantia do direito a educação diante de nosso ordenamento jurídico brasileiro, nos direcionando a análise da nossa Constituição Federal de 1988, que instituiu, por intermédio do seu artigo 214, o Plano Nacional de Educação, e análise do nosso Estatuto da Criança e Adolescente, bem como de determinadas leis relacionadas ao tema.

No terceiro e último tópico do nosso artigo abordaremos a garantia existente do direito à educação no Plano Internacional, ressalvando a importância da equidade e da justiça distributiva, cuja preocupação primordial é a de remediar as injustiças causadas pelas desigualdades sociais.

Ainda trataremos no tópico em questão, da dignidade da pessoa humana como meio de efetivação do direito à educação, e do direito à educação no Pacto Internacional de direitos econômicos, sociais e culturais de 1966, adotada pela Resolução no 2.200-A, da Assembleia Geral das Nações Unidas, adotado pelo Brasil em 1992.

\section{CONTORNOS GERAIS DA EDUCAÇÃo BÁSICA NO BRASIL E NO MUNDO}

O alcance da educação básica universal, é uma meta a ser buscada em termos mundiais, é por isso que em todo o mundo vem se desenvolvendo diversas iniciativas que contemplem de forma eficiente e eficaz a causa prioritária que é a garantia de que 
até 2015, todas as crianças, de ambos os sexos, tenham recebido educação de qualidade e concluído o ensino básico.

Ao falarmos em educação básica, é preciso ressaltar que não se está se referindo apenas ao processo que o indivíduo percorre até uma alfabetização, quando se está falando em educação básica se está falando muito além da habilidade de ler e escrever, trata-se de uma ação alfabetizadora que é desenvolvida contemplando uma formação cidadã, cultural e crítica.

De acordo com a ONU, em seu Relatório de Desenvolvimento do Milênio de 2013 no mundo há pelo menos 250 milhões de crianças em idade escolar que não são capazes de ler, escrever ou contar, conforme os padrões mínimos de aprendizagem.

Segundo o Relatório de Desenvolvimento do Milênio de 2013 elaborado pela ONU, a garantia de que todos os meninos e meninas tenham oportunidade de terminar o ensino primário não será atingida até 2015, devido ao lento ritmo de expansão educacional e devido as significativas disparidades ainda existentes, principalmente em prejuízo das meninas e das crianças das zonas rurais.

Mesmo não sendo a meta alcançada, houve progressos significativos nesses quinze anos. Ainda de acordo com o relatório citado, desde 1990 aos dias atuais, a porcentagem de crianças que frequentam o ensino primário nos países em desenvolvimento passou de $80 \%$ para $90 \%$ em 2011. Além do que a taxa de alfabetização aumentou e a desigualdade de gênero frente o acesso à educação diminuiu.

No Brasil, reconhecemos os 8 Objetivos do Milênio, como diferentes formas de mudar o mundo. Com relação à segunda maneira proposta para mudar o mundo, esta diz respeito a um dos mais importantes objetivos, que deve ser considerado prioritário para qualquer Estado. Atingir o ensino básico universal é uma tarefa árdua, que apesar dos progressos não conseguiremos concluir ao final dos quinze anos estabelecidos pela Declaração do Milênio.

Para se alcançar o ensino básico universal, o Brasil tem-se apoiado em duas metas: a) garantir que, até 2015, todas as crianças, de ambos os sexos, terminem um ciclo completo de ensino básico; e b) garantir que, até 2015, as crianças de todas as 
regiões do país, independentemente de cor, raça e sexo, concluam o ensino fundamental.

No concernente ao primeiro ponto se buscou analisar e acompanhar a taxa líquida de matricula no ensino primário, a proporção dos alunos que iniciam o $1^{\circ}$ ano e atingem o $5^{\circ}$ ano e a taxa de alfabetização na faixa etária de 15 a 24 anos.

Com relação ao segundo ponto, se observou a taxa de frequência escolar líquida das pessoas de 7 a 17 anos, por grupos de idade e nível de ensino, segundo sexo e raça, nas grandes regiões brasileiras; a taxa de frequência líquida das pessoas de 7 a 17 anos de idade, segundo os quintis de rendimento familiar mensal per capita; taxa média esperada e tempo médio de conclusão da $4^{\mathrm{a}}$ e da $8^{\mathrm{a}}$ série do ensino fundamental; o índice de adequação idade-anos de escolaridade, da população de 9 a 16 anos, por regiões geográficas; o resultado do SAEB em língua portuguesa na $4^{\mathrm{a}}$ série do ensino fundamental, por redes de ensino, em escolas urbanas; os resultados do SAEB em matemática na $3^{\mathrm{a}}$ série do ensino fundamental, por redes de ensino, em escolas urbanas; e a taxa de alfabetização das pessoas de 15 a 24 anos de idade, segundo sexo, raça e situação de domicílio, nas grandes regiões brasileiras.

Como já ressaltado o objetivo de garantir para todos o acesso a educação básica não será alcançado no presente ano de 2015, porém, notáveis são os progressos durante esses quinze anos. De acordo com o Relatório de Desenvolvimento do Milênio de 2013 elaborado pela ONU, em 1990, apenas 59,9\% dos jovens na faixa etária de 15 a 24 anos possuíam pelo menos seis anos completos de estudo, o que subiu para $84 \%$ em 2012.

Além do que, o acesso à escola pelas crianças de 7 a 14 anos foi superada graças às sucessivas políticas de universalização do ensino que reduziram radicalmente as restrições de oferta de serviços educacionais.

É por isso que a importância de programas que incentivem a propagação da educação básica de qualidade para todos é cada vez mais acentuada, trata-se de um dever não só do poder público, mas de todos nós, iniciativas simples partindo da vontade de cada brasileiro podem fazer a diferença na vida de muitos que precisam de ajuda. 
Apesar das iniciativas que nós particulares devemos ter, associado com a atuação do poder público e também com o auxílio de ONGs e do terceiro setor, acreditamos que somente conseguiremos plenamente alcançar a referida meta em nosso país quando a encararmos e tratarmos como um direito fundamental, e nesta qualidade, ser encarada como inexaurível, imprescritível e irrenunciável.

Esse direito a educação básica, além de ser propriamente um direito, deve ser encarado como uma garantia, visto que mesmo conservando o caráter declaratório que o direito possui, dispõe ainda do caráter asseguratório, que serve para assegurar o direito declarado, já que um direito sem garantia não é um verdadeiro direito. Nesse sentido é o entendimento de Ferrajoli (2004, pág.59):

"Esta tesis, cuya formulación clásica de debe a Hans Kelsen, es la última de las cuatro que al principio me He propuesto confutar. Se concreta em la la afirmación de que, más Allá de su proclamación, aun cuando sea de rango constitucional, um derecho no garantizado no sería um verdadero derecho"

Portanto, quando tratarmos a educação como um direito fundamental, garantido para todos, poderemos acreditar no cumprimento do segundo dos oito jeitos de se mudar o mundo, e assim fazer face frente aos desafios para se alcançar um efetivo desenvolvimento sustentável. Nesse contexto, passemos a análise do direito à educação no ordenamento jurídico brasileiro bem como no plano internacional.

\section{A GARANTIA DO DIREITO A EDUCAÇÃO E O ORDENAMENTO JURÍDICO BRASILEIRO}

Começamos por citar o art. 205 da Constituição Federal, que assegura a educação como sendo um direito de todos, sem qualquer discriminação, in verbis:

"Art. 205. A educação, direito de todos e dever do Estado e da família, será promovida e incentivada com a colaboração da sociedade, visando ao pleno desenvolvimento da pessoa, seu preparo para o exercício da cidadania e sua qualificação para o trabalho."

Assim, em sintonia com a garantia do direito a educação previsto na 
Constituição Brasileira, o Estatuto da Criança e do Adolescente estabelece que, in verbis:

"Art. 53. A criança e o adolescente têm direito à educação, visando ao pleno desenvolvimento de sua pessoa, preparo para o exercício da cidadania e qualificação para o trabalho, assegurando-se-lhes:

I - igualdade de condições para o acesso e permanência na escola; II - direito de ser respeitado por seus educadores;

III - direito de contestar critérios avaliativos, podendo recorrer às instâncias escolares superiores;

IV - direito de organização e participação em entidades estudantis; V - acesso à escola pública e gratuita próxima de sua residência.

Parágrafo único. É direito dos pais ou responsáveis ter ciência do processo pedagógico, bem como participar da definição das propostas educacionais."

Nesse contexto, deve existir um empenho do Estado na materialização do direito, fazendo-se necessário, ainda, contar com o apoio dos pais e responsáveis com a finalidade de incentivar o ensino a todas as crianças e adolescentes.

“Art. 54. É dever do Estado assegurar à criança e ao adolescente:

I - ensino fundamental, obrigatório e gratuito, inclusive para os que a ele não tiveram acesso na idade própria;

II - progressiva extensão da obrigatoriedade e gratuidade ao ensino médio;

III - atendimento educacional especializado aos portadores de deficiência, preferencialmente na rede regular de ensino;

IV - atendimento em creche e pré-escola às crianças de zero a seis anos de idade;

V - acesso aos níveis mais elevados do ensino, da pesquisa e da criação artística, segundo a capacidade de cada um;

VI - oferta de ensino noturno regular, adequado às condições do adolescente trabalhador;

VII - atendimento no ensino fundamental, através de programas suplementares de material didático-escolar, transporte, alimentação e assistência à saúde.

$\S 1^{\circ} \mathrm{O}$ acesso ao ensino obrigatório e gratuito é direito público subjetivo.

$\S 2^{\circ} \mathrm{O}$ não oferecimento do ensino obrigatório pelo poder público ou sua oferta irregular importa responsabilidade da autoridade competente.

$\S 3^{\circ}$ Compete ao poder público recensear os educandos no ensino fundamental, fazer-lhes a chamada e zelar, junto aos pais ou responsável, pela frequência à escola.

Art. 55. Os pais ou responsável têm a obrigação de matricular seus filhos ou pupilos na rede regular de ensino."

Para que seja garantido esse direito fundamental, a Constituição de 1988, vigente em nosso país, em seu art. 214 institui o Plano Nacional de Educação, o qual delineia os seus objetivos e metas a serem seguidas, tendo duração decenal, 
quando então é renovado, e elaborado novo plano.

"Art. 214. A lei estabelecerá o plano nacional de educação, de duração decenal, com o objetivo de articular o sistema nacional de educação em regime de colaboração e definir diretrizes, objetivos, metas e estratégias de implementação para assegurar a manutenção e desenvolvimento do ensino em seus diversos níveis, etapas e modalidades por meio de ações integradas dos poderes públicos das diferentes esferas federativas que conduzam a: (Redação dada pela Emenda Constitucional $n^{\circ} 59$, de 2009)

I - erradicação do analfabetismo;

II - universalização do atendimento escolar;

III - melhoria da qualidade do ensino;

IV - formação para o trabalho;

V - promoção humanística, científica e tecnológica do País.

VI - estabelecimento de meta de aplicação de recursos públicos em educação como proporção do produto interno bruto. (Incluído pela Emenda Constitucional $n^{\circ} 59$, de 2009)"

$\mathrm{O}$ art. $2^{\circ}$ da Lei 13.005 , de 25 de julho de 2014 , que promove o plano nacional de educação para o período de 2014 à 2014, estabelece as diretrizes traçadas para erradicar as desigualdades históricas e promover a educação como direito de todos.

Senão vejamos:

“Art. 20 São diretrizes do PNE:

I - erradicação do analfabetismo;

II - universalização do atendimento escolar;

III - superação das desigualdades educacionais, com ênfase na promoção da cidadania e na erradicação de todas as formas de discriminação;

IV - melhoria da qualidade da educação;

V - formação para o trabalho e para a cidadania, com ênfase nos valores morais e éticos em que se fundamenta a sociedade;

VI - promoção do princípio da gestão democrática da educação pública;

VII - promoção humanística, científica, cultural e tecnológica do País;

VIII - estabelecimento de meta de aplicação de recursos públicos em educação como proporção do Produto Interno Bruto - PIB, que assegure atendimento às necessidades de expansão, com padrão de qualidade e equidade;

IX - valorização dos (as) profissionais da educação;

$\mathrm{X}$ - promoção dos princípios do respeito aos direitos humanos, à diversidade e à sustentabilidade socioambiental."

Sobre o tema, importante mencionarmos a meta 4 do Plano Nacional de

Educação, a qual tem como objetivo: 
"universalizar, para a população de 4 (quatro) a 17 (dezessete) anos com deficiência, transtornos globais do desenvolvimento e altas habilidades ou superdotação, o acesso à educação básica e ao atendimento educacional especializado, preferencialmente na rede regular de ensino, com a garantia de sistema educacional inclusivo, de salas de recursos multifuncionais, classes, escolas ou serviços especializados, públicos ou conveniados."

Ademais, na forma como estabelece o art. $5^{\circ}$ da Lei 9.394, de 20 de dezembro de 1996, o aceso a educação básica é um direito obrigatório e subjetivo de todos os cidadãos, o que obriga o poder público a recensear anualmente as crianças e adolescentes, bem como jovens e adultos, ainda que não mais estejam em idade escolar, fazendo a chamada pública e zelando para que seja garantida a frequência dos estudantes nas escolas.

Por sua vez, o art. 8 da Lei 9.394/1996 dispõe que deverá haver uma cooperação entre os Estados, Municípios e Distrito Federal no sentido de garantir, dentre outras necessidades, o atendimento das necessidades específicas na educação especial, de maneira a operacionalizar o sistema educacional inclusivo.

Em relação aos objetivos para assegurar a educação básica de qualidade, buscando-se a alfabetização de todos e desenvolvimento da escolaridade, o Plano Nacional de Educação traça 20 (vinte) metas a seres seguidas, dentre as quais destacamos a meta 7 (sete) e 9 (nove), respectivamente:

"Meta 7: fomentar a qualidade da educação básica em todas as etapas e modalidades, com melhoria do fluxo escolar e da aprendizagem, de modo a atingir as seguintes médias nacionais para o Ideb: 6,0 nos anos iniciais do ensino fundamental; 5,5 nos anos finais do ensino fundamental; 5,2 no ensino médio.

[...]

Meta 9: elevar a taxa de alfabetização da população com 15 (quinze) anos ou mais para 93,5\% (noventa e três inteiros e cinco décimos por cento) até 2015 e, até o final da vigência deste PNE, erradicar o analfabetismo absoluto e reduzir em $50 \%$ (cinquenta por cento) a taxa de analfabetismo funcional."

Muito embora estejam delimitadas as responsabilidades e definidas as metas, o grande desafio é fazer com que existe uma articulação diligente, que promova a atuação conjunta de todos os entes federativos, através do planejamento de programas de incentivo e divulgação do ensino, repasse de verbas para o setor educacional, 
didáticas de ensino eficientes e adequadas as diferentes necessidades regionais e especiais dos alunos, de forma a desestimular as diferentes formas de desigualdade.

Sendo assim, para que as metas traçadas sejam alcançadas, não se pode esquecer do papel desempenhado pelos profissionais da educação, o que requer políticas, não apenas de valorização de salários, mas também de incentivo a programas de aperfeiçoamento do ensino e reconhecimento de direitos, que venham a fortalecer a classe e estimular as utilização de estratégias didático-pedagógicas.

Assim, como prioridades na redução das desigualdades educacionais tem-se que aumentar o período em que a população dedica-se aos estudos e aprimorar a qualidade do ensino e a diminuição das desigualdades entre as regiões. Para a mencionada autora (GIAMBIAGI; PORTO, 2013, p.383):

\begin{abstract}
"As discussões acima indicam que as políticas públicas regionais necessárias para o Brasil hoje devem conter três objetivos principais: (i) reduzir as desigualdades em educação, considerando tanto a qualidade quanto a quantidade disponível; (ii) reduzir possíveis distorções institucionais hoje existentes nas regiões mais pobres que possam estar atrasando-as e restringindo a oferta de educação de qualidade para uma parte não desprezível da população; e (iii) acelerar o processo de convergência para novos patamares de desigualdades regionais após a redução de seu equilíbrio a partir de políticas de redução das desigualdades em capital humano e de distorções institucionais relevantes."
\end{abstract}

Nesses termos, para que o plano de educação nacional venha a obter êxito, há que se pensar em esforços para combater as desigualdades históricas do País, ultrapassando as barreiras de acesso e permanência no ensino, de acordo com as necessidades e carências dos diferentes locais, observadas as especificidades da população.

Dessa maneira, para que isto aconteça, destaca-se o importante papel do Estado em coordenar as ações, de maneira a fiscalizar o número de matrículas em todas as escolas nos diversos Municípios do País, além de viabilizar a execução de avaliações periódicas que garantam o monitoramento do ensino e contribuam para implementar políticas de incentivo a educação de qualidade. 


\title{
4 A GARANTIA DO DiREITO À EDUCAÇÃO NO PLANO INTERNACIONAL
}

Daremos inicio a este tópico falando sobre o que vem a ser equidade. Sobre equidade, entendemos que a mesma decorre da parcela da qual cada individuo colabora com a sociedade, cabendo a este a remuneração por aquilo que contribuiu, podendo assim, fazer uma ponte do significado de equidade com o de justiça .Neste mesmo sentido, podemos citar o pensamento de Amartya Sen (PNUD, 2011, p. 21):

\begin{abstract}
"[...] De hecho, la igualdad no es necesaria ni suficiente para la equidad. Las diferencias personales llevan a diferentes resultados, incluso cuando las oportunidades y el acceso a recursos son idénticos. [...] También influyen las características personales: los grupos pobres y desfavorecidos, inclusive las personas con discapacidades mentales o físicas, necesitan tener mayor acceso a bienes y servicios públicos para lograr igualdad de capacidad."
\end{abstract}

Atualmente a equidade refere-se principalmente a justiça distributiva, ou seja, preocupa-se em corrigir as injustiças.

Neste contexto, analisemos pois, a educação no plano internacional no tocante a atingir o ensino básico universal, assegurando assim o mínimo existencial para todos, como nos explica Ricardo Lobo Torres (1989, p. 36):

\begin{abstract}
"O mínimo existencial corresponde às necessidade básicas que integram o princípio da liberdade, e por isso são fundamentos constitucionais e não se confundem com as questões de justiça básica. Seu fundamento, por conseguinte, está nas condições para o exercício da liberdade; sem o mínimo necessário à existência cessam as condições iniciais para a liberdade. Por exemplo, "a liberdade de expressão só se afirma se as pessoas souberem ler e escrever, donde se conclui que o ensino da leitura e da escrita é mínimo existencial".
\end{abstract}

Nesta linha de raciocínio, a educação constitui um mínimo existencial uma vez que, observássemos que a educação é um pressuposto para o exercício da plena democracia e por conseguinte da cidadaniaLogo, podemos dizer que cabe ao Estado assegurar que todos os cidadãos tenham acesso a este direito fundamental. 
Realcemos ainda, que a educação fora reconhecida em diversos países como um direito fundamental, e consubstanciado no reconhecimento de sua importância para a promoção da dignidade da pessoa humana, em especial pela sua imprescindibilidade para o consciente exercício da cidadania. Isto não resulta em mera positivação, mas essencialmente em sua exigibilidade por qualquer indivíduo que por ela, pode expandir "a capacidade universal humana de participar, de forma ativa e inteligente, da produção econômica e da gestão política, e de pensar e sentir na dimensão filosófica e artística".

Assim, nos torna claro que a educação é observada como um eficaz instrumento para a construção da dignidade, pois, conforme Marcia Cristina de Souza Alvin (2006, p. 183):

"o reconhecimento da dignidade da pessoa humana é operação que necessita de consciência viva e plena, sintonizada com o ambiente vital e com a sociedade. E a maneira mais segura de garantir essa consciência é o investimento, pessoal e social, na educação."

Devido a universalidade dos referidos direitos fundamentais, logo após a Segunda Guerra Mundial, houve uma maior preocupação no intuito de se conferir contorno normativo ao seu reconhecimento. A consagração do direito à educação, tem sido constantemente mencionada nas diversas legislações, cartas de princípios e acordos internacionais que buscam estabelecer a pauta de direitos da dignidade da pessoa humana.

Nessa direção podemos exemplificar diversas legislações que assim asseguram:

- A Declaração Universal dos Direitos do Homem, proclamada pela Resolução 217 A (III) da Assembléia Geral das Nações Unidas, de 10 de dezembro de 1948,aduz em seu art. XXVI, que:

"1. Toda pessoa tem direito à instrução. A instrução será gratuita, pelo menos nos graus elementares e fundamentais. A instrução elementar será obrigatória. A instrução técnico profissional será acessível a todos, bem como a instrução superior, está baseada no mérito. 2. A instrução será orientada no sentido do pleno desenvolvimento da personalidade humana e do fortalecimento do respeito pelos direitos do homem e pelas liberdades fundamentais. A instrução promoverá a compreensão, a tolerância e a amizade entre todas as nações e grupos raciais ou religiosos, e coadjuvará as atividades das Nações Unidas em prol da manutenção da paz. 3. Os pais têm prioridade de direito na escolha do gênero de instrução que será ministrada a seus filhos." 
A Declaração Americana dos Direitos e Deveres do Homem, aprovada pela Resolução XXX, da IX Conferência Internacional Americana, realizada em abril de 1948, na Cidade de Bogotá, dispôs, em seu art. XII, que:

\begin{abstract}
"Toda pessoa tem direito à educação, que deve inspirar-se nos princípios de liberdade, moralidade e solidariedade humana. Tem, outrossim, direito a que, por meio dessa educação, lhe seja proporcionado o preparo para subsistir de uma maneira digna, para melhorar o seu nível de vida e para poder ser útil à sociedade. $\mathrm{O}$ direito à educação compreende o de igualdade de oportunidade em todos os casos, de acordo com os dons naturais, os méritos e o desejo de aproveitar os recursos que possam proporcionar a coletividade e o Estado. Toda pessoa tem o direito de que lhe seja ministrada gratuitamente, pelo menos, a instrução primária".
\end{abstract}

Ainda a Carta Internacional Americana de Garantias Sociais, aprovada na mesma ocasião, assentou, em seu art. $4^{\circ}$, que:

\begin{abstract}
"todo trabalhador tem direito a receber educação profissionalizante e técnica para aperfeiçoar suas aptidões e conhecimentos, obter maiores remunerações de seu trabalho e contribuir de modo eficiente para o desenvolvimento da produção. Para tanto, o Estado organizará o ensino dos adultos e a aprendizagem dos jovens, de tal modo que permita assegurar o aprendizado efetivo de um ofício ou trabalho determinado, ao mesmo tempo em que provê a sua formação cultural, moral e cívica".
\end{abstract}

A Declaração dos Direitos da Criança, adotada pela Assembléia das Nações

Unidas de 20 de novembro de 1959, dispôs, em seu princípio $7^{\circ}$, que:

"a criança terá direito a receber educação, que será gratuita e compulsória pelo menos no grau primário. Ser-lhe-á propiciada uma educação capaz de promover a sua cultura geral e capacitá-la a, em condições de iguais oportunidades, desenvolver as suas aptidões, sua capacidade de emitir juízo e seu senso de responsabilidade moral e social, e a tornar-se membro útil da sociedade."

A Conferência Geral da Organização das Nações Unidas para a Educação celebrou, em 14 de dezembro de 1960, a Convenção Relativa à Luta Contra a Discriminação no Campo do Ensino. A Convenção, dentre outras hipóteses, 
considerou o termo discriminação como abrangente de qualquer iniciativa que terminasse por:

a) privar qualquer pessoa ou grupo de pessoas do acesso aos diversos tipos ou graus de ensino; b) limitar a nível inferior a educação de qualquer pessoa ou grupo; e c) impor a qualquer pessoa ou grupo de pessoas condições incompatíveis com a dignidade do homem.

Segundo o art. IV da Convenção, além de eliminar as formas de discriminação, os Estados Partes devem formular, desenvolver e aplicar uma política nacional que vise a promover a igualdade de oportunidade em matéria de ensino e, principalmente:

\begin{abstract}
"a) tornar obrigatório e gratuito o ensino primário; generalizar e tornar acessível a todos o ensino secundário sob suas diversas formas; tornar igualmente acessível a todos o ensino superior em função das capacidades individuais; assegurar a execução por todos da obrigação escolar prescrita em lei; b) assegurar em todos os estabelecimentos públicos do mesmo grau um ensino do mesmo nível e condições equivalentes no que diz respeito à qualidade do ensino dado; c) encorajar e intensificar, por métodos apropriados, a educação de pessoas que não receberam instrução primária ou que não a terminaram e permitir que continuem seus estudos em função de suas aptidões; d) assegurar sem discriminação a preparação ao magistério."
\end{abstract}

Citemos ainda o Pacto Internacional de Direitos Econômicos, Sociais e Culturais, adotado pela Resolução no 2.200-A, da Assembleia Geral das Nações Unidas, de 16 de dezembro de 1966, em seu art. 13, dispôs que:

"1. Os Estados Partes no presente Pacto reconhecem o direito de toda pessoa à educação. Concordam em que a educação deverá visar ao pleno desenvolvimento da personalidade humana e do sentido de sua dignidade e fortalecer o respeito pelos direitos humanos e liberdades fundamentais. Concordam ainda em que a educação deverá capacitar todas as pessoas a participar efetivamente de uma sociedade livre, favorecer a compreensão, a tolerância e a amizade entre todas as nações e entre todos os grupos raciais, étnicos ou religiosos e promover as atividades das Nações Unidas em prol da manutenção da paz. 2. Os Estados Partes no presente Pacto reconhecem que, com o objetivo de assegurar o pleno exercício desse direito: a) a educação primária deverá ser obrigatória e acessível gratuitamente a todos; b) a educação secundária em suas 
diferentes formas, inclusive a educação secundária técnica e profissional, deverá ser generalizada e tornar-se acessível a todos, por todos os meios apropriados e, principalmente, pela implementação progressiva do ensino gratuito; c) a educação de nível superior deverá igualmente tornar-se acessível a todos, com base na capacidade de cada um, por todos os meios apropriados e, principalmente, pela implementação progressiva do ensino gratuito; d) dever-seá fomentar e intensificar, na medida do possível, a educação de base para aquelas pessoas que não receberam educação primária ou não concluíram o ciclo completo de educação primária; e) será preciso prosseguir ativamente o desenvolvimento de uma rede escolar em todos os níveis de ensino, implementar-se um sistema adequado de bolsas de estudo e melhorar continuamente as condições materiais do corpo docente (...)."

Além dos já mencionados, deve ser lembrada a Declaração Mundial de Educação para Todos, adotada na Conferência de Jomtien, na Tailândia que faz menção a satisfação das Necessidades Básicas de Aprendizagem e em seu preâmbulo ressalta:

Há mais de quarenta anos, as nações do mundo afirmaram na Declaração Universal dos Direitos Humanos que "toda pessoa tem direito à educação". No entanto, apesar dos esforços realizados por países do mundo inteiro para assegurar o direito à educação para todos, persistem as seguintes realidades:

- $\quad$ mais de 100 milhões de crianças, das quais pelo menos 60 milhões são meninas, não têm acesso ao ensino primário;

- $\quad$ mais de 960 milhões de adultos - dois terços dos quais mulheres são analfabetos, e o analfabetismo funcional é um problema significativo em todos os países industrializados ou em desenvolvimento; - mais de um terço dos adultos do mundo não têm acesso ao conhecimento impresso, às novas habilidades e tecnologias, que poderiam melhorar a qualidade de vida e ajudá-los a perceber e a adaptar-se às mudanças sociais e culturais; e

- mais de 100 milhões de crianças e incontáveis adultos não conseguem concluir o ciclo básico, e outros milhões, apesar de concluí-lo, não conseguem adquirir conhecimentos e habilidades essenciais.

Ressalta ainda, esta declaração, que mesmo com esses dados preocupantes o mundo inteiro enfrenta outros diversos problemas, como por exemplo a crise 
financeira em muitos países, a estagnação e decadência econômica, aumento da população, guerras civis, violência, etc. Resultando assim num embaraço aos esforços dispensados no intuito de satisfazer as necessidades básicas de aprendizagem.

Há quem diga que estes, somados a outros, embaraçaram ainda mais os avanços da educação básica em muitos países pouco desenvolvidos.

No entanto, neste novo século com o avanço da tecnologia e imbuídos de esperanças, torcemos para que haja uma maior cooperação entre as nações e avanços significativos. O conhecimento é repassado de forma rápida e quase que instantânea e há uma nova forma de comunicação, como bem disse a própria Declaração há tempos: essas novas forças, combinada com a experiência acumulada de reformas, inovações, pesquisas, e com o notável progresso em educação registrado em muitos países, fazem com que a meta de educação básica para todos - pela primeira vez na história - seja uma meta viável. Restando-nos apenas a torcer e cumprir o nosso papel de cidadão para que possa se concretizar a referida meta.

\subsection{A dignidade da pessoa humana como meio à efetivação do direito à educação}

A dignidade da pessoa humana representa o valor essencial do Estado moderno no seio do qual seu respeito deve ser garantido, mediante o reconhecimento de direitos capazes de promovê-la. Sintetiza, em si, todos os direitos fundamentais. A elevação da educação a um direito consubstanciou-se no reconhecimento de sua importância para a promoção da dignidade da pessoa humana, em especial pela sua imprescindibilidade para o consciente exercício da cidadania. Seu reconhecimento não resulta em mera positivação, mas essencialmente em sua exigibilidade por qualquer indivíduo que por ela, pode expandir "a capacidade universal humana de participar, de forma ativa e inteligente, da produção econômica e da gestão política, e de pensar e sentir na dimensão filosófica e artística".

Assim, nos torna claro que a educação é observada como um eficaz instrumento para a construção da dignidade, pois, conforme Marcia Cristina de Souza Alvin (2006, p. 183): 


\begin{abstract}
"o reconhecimento da dignidade da pessoa humana é operação que necessita de consciência viva e plena, sintonizada com o ambiente vital e com a sociedade. E a maneira mais segura de garantir essa consciência é o investimento, pessoal e social, na educação."
\end{abstract}

Neste sentido, o direito à educação pode ser compreendido como, corolário do direito à dignidade da pessoa humana, no que diz respeito ao livre e pleno desenvolvimento de sua autonomia.

\title{
5 CONCLUSÃO
}

Ao longo deste artigo, procuramos explanar a educação como um direito primordial garantido a toda criança e adolescente tanto no plano nacional $\mathrm{cm}$ internacional.

Mostramos aqui os dispositivos de proteção para a garantir a educação básica, e podemos perceber que apesar de já nos encontramos em 2015, ainda não alcançamos o objetivo da educação básica de qualidade para todas as crianças e adolescentes, porém, tivemos um enorme progresso no que tange a erradicação do analfabetismo e a inclusão das nossas crianças na escola, sem fazer distinção entre gêneros. O caminho para alcançarmos o modelo ideal ainda estamos a percorrer, uma vez que já nos encontramos no ano limite para atingir este objetivo e ainda não o fizemos plenamente, mas já é de fácil percepção que estamos trilhando o caminho certo, basta acompanhar os número oficiais, logo, concluímos dizendo que com persistência,organização e empenho do Poder Público é sim possível garantir a dignidade da pessoa humana através da efetivação do direito à educação.

\section{REFERÊNCIAS BIBLIOGRÁFICAS}

ALVIN, Márcia Cristina de Souza. A Educação e a dignidade da pessoa humana. In. Bittar, Eduardo C. B. e Ferraz, Anna Cândida da Cunha. Direitos Humanos Fundamentais: positivação e concretização. São Paulo: Edifieo, 2006.

BRASIL. Constituição (1988). Constituição da república federativa do brasil: promulgada em 5 de outubro de 1988. Disponível em <http://www.planalto.gov.br/ccivil_03/constituicao/constituicao.htm>. 
Decreto 3.298, de 20 de dezembro de 1999. Regulamenta a lei n. 7.853 , de 24 de outubro de 1989, dispõe sobre a política nacional para a integração da pessoa portadora de deficiência, consolida as normas de proteção, e dá outras providências. Disponível em <http://www.planalto.gov. br/ccivil_03/decreto/d3298.htm>.

Decreto 7.611, de 17 de novembro de 2011. Dispõe sobre a educação especial, o atendimento educacional especializado e dá outras providências. Disponível em <http://www.planalto.gov.br/ccivil_03/_ato2011-2014/2011/decreto/ d7611.htm>.

. Decreto 6.949, de 25 de agosto de 2009. Promulga a convenção internacional sobre os direitos das pessoas com deficiência e seu protocolo facultativo, assinados em Nova York, em 30 de março de 2007. Disponível em: <http://www.planalto.gov.br/ccivil_03/_ato20072010/2009/decreto/d694 9.htm>.

. Lei 7.853, de 24 de outubro de 1989. Dispõe sobre o apoio às pessoas portadoras de deficiência, sua integração social, sobre a coordenadoria nacional para integração da pessoa portadora de deficiência - CORDE, institui a tutela jurisdicional de interesses coletivos ou difusos dessas pessoas, disciplina a atuação do ministério público, define crimes, e dá outras providências. Disponível em: <http://www.planalto.gov.br/ccivil_03/leis/17853.htm>.

. Lei 9.394, de dezembro de 1996. Estabelece as diretrizes e bases da educação nacional. Disponível em <http://www.planalto.gov.br/ccivil_ 03/leis/19394.htm>.

Lei 10.098, de 19 de dezembro de 2000. Estabelece normas gerais e critérios básicos para a promoção da acessibilidade das pessoas portadoras de deficiência ou com mobilidade reduzida, e dá outras providências. Disponível em <http://www.planalto.gov.br/ccivil_03/leis/1100 98.htm>.

. Lei n. 13.005, de 25 de junho de 2014. Aprova o plano nacional de educação - PNE e dá outras providências. Disponível em <http://www.planalto.gov.br/CCIVIL_03/_Ato2011-2014/2014/Lei/L13005.htm>.

Portal ODM. Acompanhamento brasileiro dos objetivos de desenvolvimento do milênio. Disponível em: <http://www.unric.org/html/ portuguese/mdg/MDG-PT-2013.pdf >.

FERRAJOLI, Luigi. Derechos y garantias: la ley del más débil. Madrid: EDITORIAL TROTTA, $4^{\mathrm{a} e d .,} 2004$.

GIAMBIAGI, Fabio; PORTO, Claudio. Propostas para o governo 2015/2018: agenda para um país próspero e competitivo. Rio de janeiro: Elsevier, 2013.

ONU. Relatório sobre os Objetivos do Milênio de 2013. Disponível em: <http:// www.unric.org/html/portuguese/mdg/MDG-PT-2013.pdf>. 
PNUD. Informe sobre desarollo humano 2011. Disponível em: <http:// www.zaragoza.es/contenidos/medioambiente/onu/issue07/1108-spa.pdf>.

SACHS, Jeffrey. O fim da miséria. Tradução de Pedro Maia Soares. São Paulo: Companhia das Letras, 2005.

TORRES, Ricardo Lobo. A metamorfose dos direitos sociais em mínimo existencial. In: Revista de Direito Administrativo. Rio de Janeiro: Renovar, n. 177, julho/setembro 1989. 